\title{
HIGHER EDUCATION IN THE WORLD 4
}

Higher Education's Commitment to Sustainability: from Understanding to Action

LA EDUCACIÓN SUPERIOR EN EL MUNDO 4

El Compromiso de la Educación Superior con la Sostenibilidad: del Comprender al Actuar

Ha llegado a nuestras manos el informe número 4 de GUNI, publicado en idioma inglés en 341 páginas y mapas, impreso por Palgrave Macmillan, 2012, en el Reino Unido. A continuación desarrollamos la reseña bibliográfica con el propósito de interesarlos en su lectura.

GUNI (Global University Network for Education), la Red Mundial para la Innovación de la Educación Superior, fue creada en 1999 por la UNESCO (Organización de las Naciones Unidas para la Educación, la Ciencia y la Cultura), la UNU (Universidad de las Naciones Unidas) y la UPC (Universidad Politécnica de Cataluña). La GUNI trabaja en pro de la aplicación de las decisiones adoptadas en la Conferencia Mundial sobre la Educación Superior (CMES, París, 1998). Su misión es contribuir al fortalecimiento de la educación superior en todo el mundo, poniendo en práctica las decisiones adoptadas en la CMES. En concreto, por la mejora de la calidad en la enseñanza, la promoción de la innovación en la educación superior y el fortalecimiento del compromiso social de las universidades.

El informe Higher Education in the World es un trabajo colectivo que se publica dentro de la serie de la Red Mun- dial para la Innovación de la Educación Superior (GUNI) sobre el compromiso social de las universidades. Es el resultado de un análisis global y regional de la educación superior en el mundo.

Existen ya publicados tres volúmenes, con un tema concreto para cada edición. $\mathrm{El}$ informe reflexiona sobre problemas y desafíos clave a los que se enfrenta la educación superior y sus instituciones en el siglo XXI. Se trata de un reporte imprescindible para académicos, equipos de

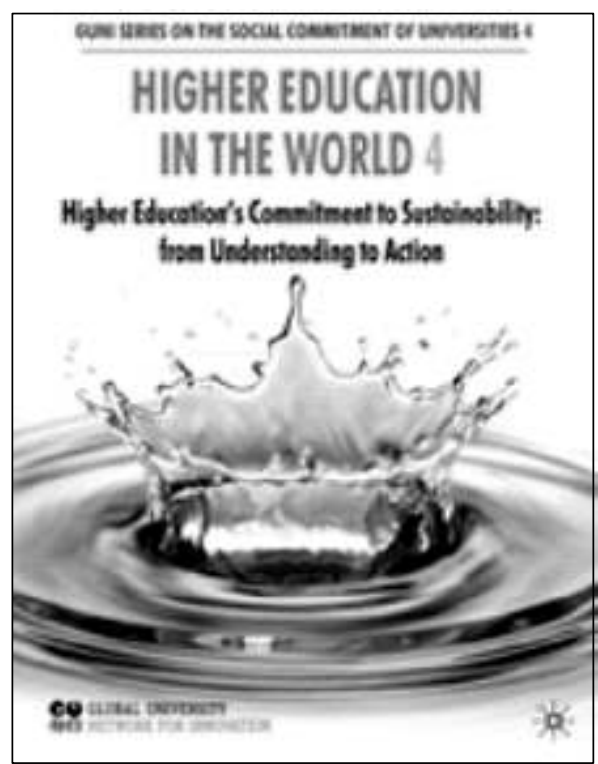


dirección y actores políticos interesados en estos temas.

El cuarto reporte Higher Education in the World 4 (La Educación Superior en el Mundo 4) - Higher Education's Commitment to Sustainability: From Understanding to Action (El Compromiso de la Educación Superior con la Sostenibilidad: Del Comprender al Actuar) analiza cómo la educación superior está abordando el reto de la sostenibilidad. El informe se inicia con una mirada a las tendencias regionales, continúa con un repaso a los temas emergentes y describe experiencias de redes y cooperaciones. Esta publicación también incluye un estudio que identifica las principales barreras que impiden la transformación de las instituciones de educación superior para contribuir a la sostenibilidad y propone soluciones para vencerlas. El informe finaliza con la presentación de algunas visiones para avanzar y pasar de la comprensión a la acción.

Este reporte incluye trabajos de 86 autores que pertenecen a 36 países del orbe. La publicación presenta seis partes. La parte I, denominada EL CONTEXTO, aborda la situación actual y sus implicaciones para la educación superior, el análisis de la relación entre la sostenibilidad y la educación superior; además se muestra un mapa de cómo las regiones están avanzando en relación con el tema. La parte II se refiere a las PERSPECTIVAS REGIONALES: ¿QUÉ SE HA LOGRADO EN ESTA ETAPA?, mostrando lo que ocurre en las universidades de África, los estados árabes, Asia Pacífico, Europa, Canadá y Estados Unidos, y finalmente, de Latinoamérica y el Caribe. La parte III, PASO DEL COMPRENDER AL ACTUAR, incluye un estudio para identificar las principales barreras que impiden la transformación de las instituciones de educación superior a contribuir con el paradigma de la sostenibilidad. La parte IV. VISIONES PARA LA TRANSFORMACIÓN, presenta algunas posibles soluciones en un marco global para avanzar de la comprensión a la acción. La parte $\mathrm{V}$ muestra un apéndice estadístico de mucha utilidad. Finalmente, la parte VI está constituida por una LECTURA ADICIONAL que presenta, de modo sistematizado, las referencias bibliográficas que ayudarán al lector a lograr un panorama de extrapolación amplísimo.

La lectura de este interesantísimo informe, sin duda, estimulará la reflexión seria y profunda para fortalecer el papel de la educación superior en la sociedad, contribuyendo a la renovación de las visiones, misiones y políticas de educación superior en todo el mundo desde una perspectiva de servicio público, la pertinencia y responsabilidad social.

La Universidad Católica Los Ángeles de Chimbote vivencia la Responsabilidad Social en un sistema transversal a los planes de estudios de las diferentes carreras profesionales. Reconocemos de este modo que las instituciones de educación superior pueden desempeñar un papel muy importante en la construcción de un modelo sostenible. Pueden ayudar a enfrentar los desafíos locales y globales, lo que fortalece a la sociedad para responder a los grandes retos mundiales.

\footnotetext{
Lic. Ascario Alberto Carrasco Torres

Docente de la Facultad de Educación y Humanidades - ULADECH Católica
} 